\title{
A Mastery-Based Learning model for an upper-level vibration analysis course
}

Dr. Kurt M DeGoede, Elizabethtown College

Professor of Engineering and Physics, Elizabethtown College. His research interests in biomechanics include developing clinical instruments for rehabilitation. Dr. DeGoede teaches upper-level undergraduate mechanical engineering and design courses and first-year foundations of engineering courses. He is also developing a collaborative study abroad program in West Africa. 


\section{A Mastery-Based Learning model for an upper-level vibration analysis course}

\section{Background}

The origins of mastery-based-learning (MBL) find a root in the idea that, with enough time, all students with the appropriate prerequisite understanding could master any new topic [1]. In a traditional grading scheme, all students progress through topics and the same rate. At the end of a unit, an exam is used to assess student mastery. All students then move on to the next unit regardless of their performance on the previous exam.

In a typical mastery-based approach, an individual student must demonstrate mastery of one topic before progressing to the next topic $[2,3,4,5]$. An MBL approach built upon a large number of tiered specific skills guarantees all students earning a particular grade in a course have demonstrated mastery of critical skills [6].

MBL courses are become more widespread in engineering curricula [7, 8, 4]. Specifically, in Mechanical Engineering, an increase in the usage of this assessment structure is emerging [9, 6, $10,11,12]$. In this assessment environment, students do master key skills at significantly higher rates $[9,10,6]$. Of course, many students must spend additional time on these key topics before proceeding to others, so the increased performance on these skills does come at the expense of other skills [6]. This trade-off is worth the cost when skills are prioritized in tiers or levels requiring mastery of the most important skills before moving into less critical skill sets.

However, using this approach can make it difficult to manage classroom sessions, with students studying different topics in parallel. Some courses may require a more structured approach to the topics, with students progressing through the content in the traditional all students at once structure.

\section{Problem Statement}

An assessment structure was desired where all students gain proficiency with core competencies in the course, and progress through course topics together. The structure must also challenge students to go beyond core competency to higher levels of mastery in most topics.

\section{Solution}

Presented here is an MBL structure for a vibration analysis course with four areas of study: Analytical Mechanics (Lagrangian Mechanics, 1-Degree-of-Freedom (DoF) Vibration, multiDoF vibration, and the Wave Equation). In each unit, an exam consists of two parts: Proficiency and Mastery.

Final grades were determined by the number of units in which students demonstrated proficiency: $+1 / 3$ letter grade for each unit where students demonstrated $90 \%$ or higher-level work on the Proficiency section of the exam. Students also earned higher grades by demonstrating competency in the Mastery problems on exams and by completing four experimental analysis and modeling projects. 


\section{Course Level Details (Methods)}

The course is a 400-level course in our multidisciplinary Engineering major - Mechanical Engineering concentration. The four units of the course cover oscillatory behavior, from a single-degree-of-freedom (1-DoF) to solving the wave equation (Table 1). The course focuses on oscillatory inputs. Step and impulse inputs are covered extensively in our control theory course. The catalog description: Lagrangian formulations for three-dimensional motion of particles and rigid bodies. Linear free and forced responses of one and multi-degree of freedom systems and simple continuous systems. Introduction to vibration control/absorption. The course objectives focus on ABET outcome 1 [13]: The students will learn to use Lagrangian mechanics to solve advanced problems in dynamics and vibrations and set up the wave equation (ABET

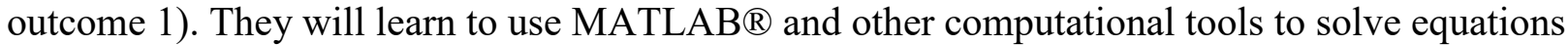
of motion, the wave equation, and model complex systems (ABET 1). Emphasis is on multidegree of freedom oscillatory systems. Students will solve realistic, complex engineering problems (multi DOF vibrating systems) using modern analytical tools (MATLAB ${ }^{\circledR}$ and Simscape Multibody ${ }^{\mathrm{TM}}$ [14]), including a special emphasis on appropriate approximation methods (ABET 1). Students will design vibration isolators (ABET 2).

Table 1: Course topics.

\begin{tabular}{|c|l|c|l|}
\hline Unit & Topic & Sessions & Assessments \\
\hline 1 & Lagrangian Mechanics & 4 & Exam I \\
\hline 2 & $\begin{array}{l}\text { 1-DoF systems and Simscape } \\
\text { Multibody }\end{array}$ & 7 & Exam II and Project 1 \\
\hline 3 & Multi-DoF Systems & 8 & $\begin{array}{l}\text { Exam III and Project 2+ } \\
\text { Simulation }\end{array}$ \\
\hline 4 & Wave Equation & 6 & Exam IV and Project 3 \\
\hline
\end{tabular}

Each of the exams is in two parts. The first section of each exam assesses the core competency of the unit. This section is called the Proficiency portion of the exam. Students must demonstrate competency to a level of $90 \%$ or higher on this section of the exam to earn credit for Proficiency in this unit. The Proficiency assessment aims to ensure all students have the skill level needed to navigate the subsequent units of the course successfully and targets comprehension of required terms, concepts, and equations and application of those understandings through a procedural analysis problem. The Mastery portion of the exam assesses less scripted open-ended analysis, synthesis, and evaluation [15]. In the Mastery

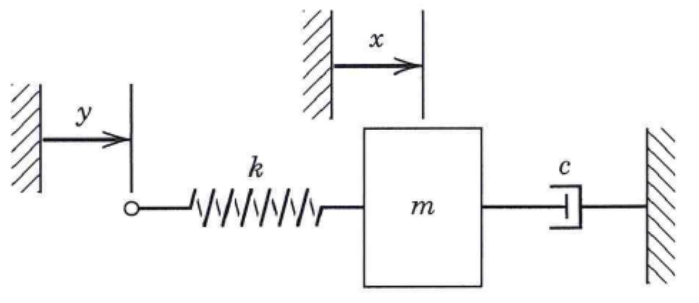

Figure 1: 1-DoF system. portion, students are required to solve problems with non-standard conditions, interpret results, and predict behavior.

In the second unit, 1-DoF systems, the Proficiency section requires the students to set up the equation of motion for a forces massspring-damper oscillator (for example, Figure 1), 
and apply the governing equation for these systems to express the response amplitude and phase shift.

In the Mastery portion of the exam, students might be asked to determine the physical characteristics of a system from reported data on the vibration of the system, or to set up and solve for the motion of a non-standard system including both steady-state and start-up effects.

In the proficiency section, before exam day, students are provided with clear information on what will be tested and the type of system of analysis. Here, the students must demonstrate competency at a level consistent with a traditional grade of $90 \%$ or higher - no conceptual errors in the analysis. Students may retake any Proficiency assessment on subsequent exam dates (Table 2). In the Mastery section, all topics or types of analysis covered in the unit homework assignments could be included. Mastery is assessed at four levels: No credit(0), Fair(1), Good(2), and Excellent(3). Students can retake any Mastery assessment on the Final Exam date.

Students also earn higher grades through experimental analysis and simulation project assignments. In these projects, students perform experimental analyses of physical systems: 1 DoF, 4 DoF, and continuous, approximate non-linear behavior and damping, compare to theoretical expectations and simulate using the MATLAB ${ }^{\circledR}$ ode 45 and Simscape Multibody ${ }^{\mathrm{TM}}$ simulations. Each project assignment requires a formal write-up and is assessed on a 4 point scale: Poor (1): some portions missing or demonstrating poor understanding of the system, Fair (2): some portions incomplete or work is sloppy and unprofessional, Good (3): minor errors in analysis or writing/formatting, Excellent (4): outstanding report. As with the Mastery exams assessments, the four scores are averaged at the end of the semester for grading (Table 2).

Altogether, students earn a C-level grade by demonstrating competency on the proficiency level exams combined with "fair" work on take-home applications of the material. B-level grades require some combination of stronger work in the take-home applications or demonstrating higher-order mastery of some of the course topics. A-level grades require both strong work on the application assignments and full mastery of most of the course topics. 
Table 2: Grading Summary.

\begin{tabular}{|c|c|c|c|c|}
\hline \multicolumn{5}{|c|}{ Grading System } \\
\hline Item & Proficiency & $\begin{array}{l}\text { Proficiency } \\
\text { Attempts }\end{array}$ & Mastery ${ }^{\varphi}$ & $\begin{array}{l}\text { Mastery } \\
\text { Attempts }\end{array}$ \\
\hline Exam 1 & $+1 / 3$ grade & 4 & $+1 / 3$ grade & $2^{*}$ \\
\hline Exam 2 & $+1 / 3$ grade & 3 & $+1 / 3$ grade & $2^{*}$ \\
\hline Exam 3 & $+1 / 3$ grade & 2 & $+1 / 3$ grade & $2^{*}$ \\
\hline Exam 4 (FE week) & $+1 / 3$ grade & 1 & \multicolumn{2}{|c|}{ N/A } \\
\hline Project $1^{\delta}$ & $+1 / 3$ grade & 1 & \multicolumn{2}{|c|}{ N/A } \\
\hline Project $2^{\delta}$ & $+1 / 3$ grade & 1 & $+1 / 3$ grade & 1 \\
\hline Project $3^{\delta}$ & $+1 / 3$ grade & 1 & \multicolumn{2}{|c|}{ N/A } \\
\hline Homework $^{* *}$ & $+1 / 3$ grade & Cumulative & \multicolumn{2}{|c|}{ N/A } \\
\hline \multicolumn{5}{|c|}{$\begin{array}{l}{ }^{\varphi} \text { Mastery is assessed at four levels: No credit(0), Fair(1), Good(2) and Excellent(3). The thre } \\
\text { Mastery scores are averaged at the end of the semester. If you average } 0.50-1.49:+1 / 3 \text { letter } \\
\text { grade; } 1.50-2.49:+2 / 3 \text { letter grade; } 2.50-3.00:+1 \text { full letter grade }\end{array}$} \\
\hline \multirow{2}{*}{\multicolumn{5}{|c|}{$\begin{array}{l}{ }^{*} \text { On the final, you can retake any Mastery assessments. Highest score is used in grading. } \\
\delta \text { At the end of the term, your average assessment across the } 4 \text { evaluations }(2 \text { for the second } \\
\text { project) will determine the grade modification. If you average } 0.50-1.49:+1 / 3 \text { letter grade; } \\
1.50-2.49:+2 / 3 \text { letter grade; } 2.50-3.49:+1 \text { full letter grade } 3.5+:+4 / 3 \text { letter grade. }\end{array}$}} \\
\hline & & & & \\
\hline \multicolumn{5}{|c|}{$\begin{array}{l}\text { ** To meet HW expectations, students must average } 90 \% \text { on Homework assignments }(20 \% \\
\text { lowest of Homework will be dropped) }\end{array}$} \\
\hline \multicolumn{5}{|c|}{$\begin{array}{l}\text { Grades start at } \mathrm{F} \text {. There are } 12 \text { possible increases in the grade. Meet any } 11 \text { for a Grade of } \mathrm{A} \\
\text { (any } 5 \text { for } \mathrm{C} \text {, any } 8 \text { for } \mathrm{B}, \text { etc.). }\end{array}$} \\
\hline
\end{tabular}

\section{Results}

Parallel data were available for the first 3 of 4 units to compare performance under this model to a traditional grading scheme. Traditional exam grading (2018) was compared to the described MBL system in 2019. In 2018, exams featured core proficiency problems (one or two) along with problems that stretched students to demonstrate a higher-order understanding of the material. Students had the opportunity to take an optional post-exam quiz retesting them on the core principles with the grade averaged with the original exam grade. Only $47 \%$ of the students scoring less than $90 \%$ on the core principles problems took advantage of this opportunity. In the end, $53 \%$ of the students demonstrated $90 \%+$ competency on the proficiency level analyses for all three units (Figure 2).

In 2019, Students scored much higher on the original proficiency problems on the typical exam: $85 \%$ of the students scored $90 \%$ or higher on these problems, compared to $25-45 \%$ of the students scoring this high on the 2018 exams. The 2019 students also took retake assessments on skills they did not demonstrate competency on at twice the rate of the 2018 students. At the end 
of the semester, $95 \%$ of the students had demonstrated competency on the proficiency level analyses for all three units.

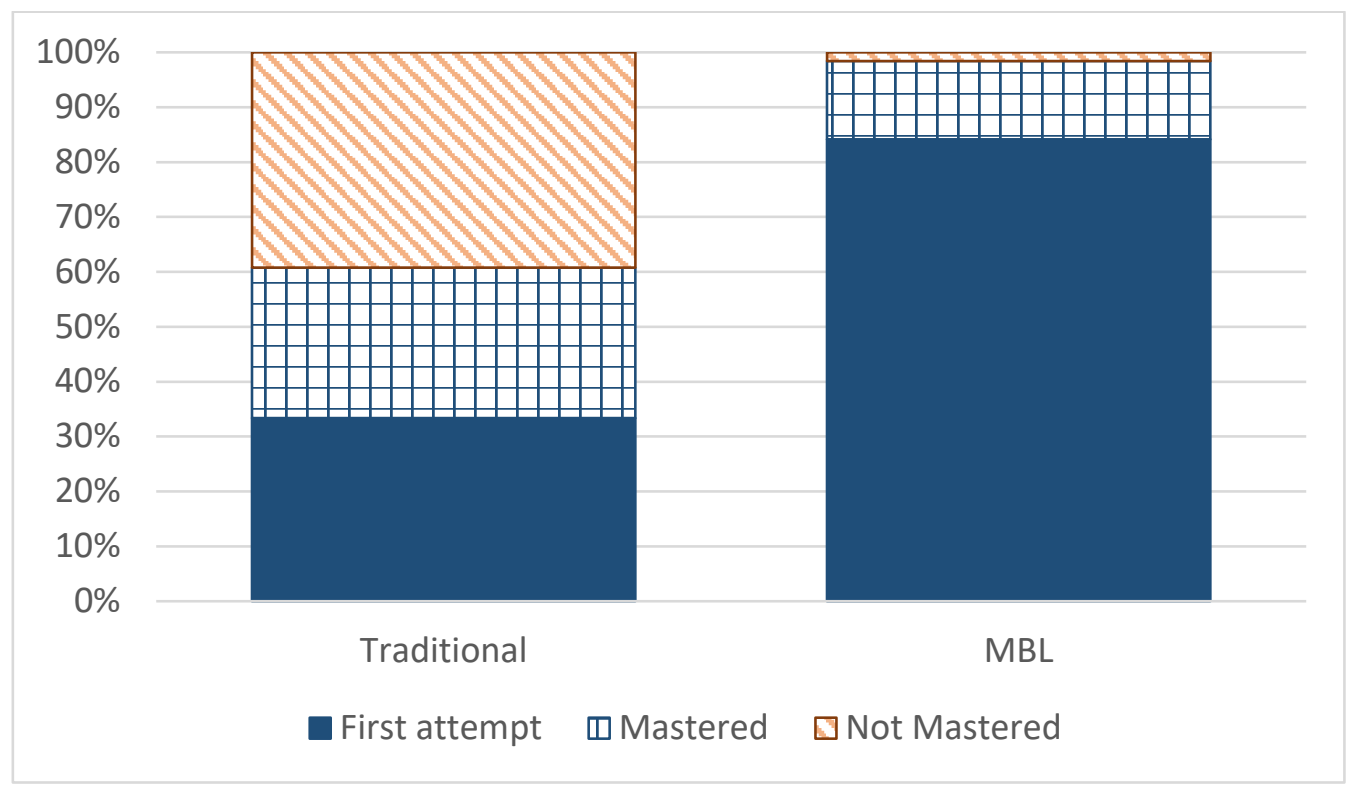

Figure 2: Average Performance on Proficiency Assessments. Solid green bar indicates Mastery demonstrated on the first attempt. Dotted green bar indicates Mastery demonstrated by the end of the semester. Red hashed bar indicates mastery not demonstrated.

Success on the Mastery level problems did not change significantly from 2018 to 2019. Performance on the project type assignments was also unchanged. Final course grades were also similar between the two populations, with an average grade of B- in both groups (Figure 3). 


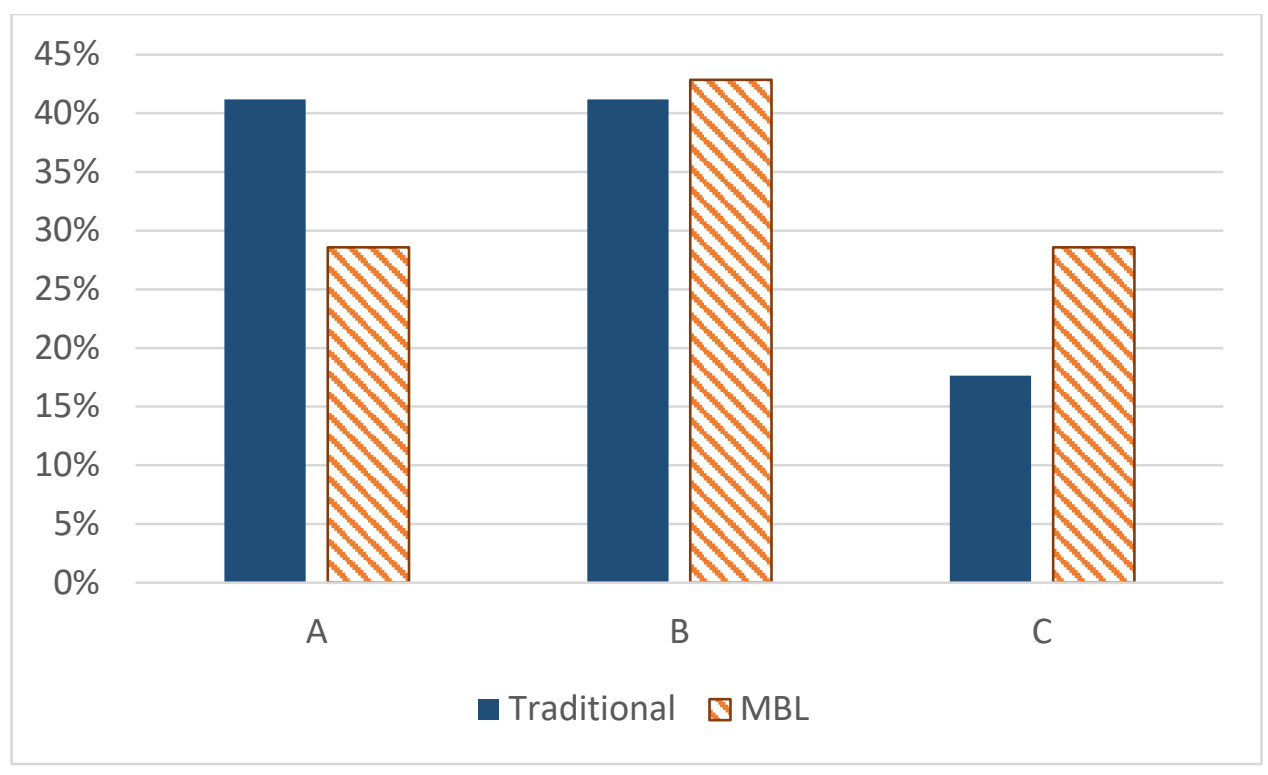

Figure 3: Percentage of students receiving a final course grade in each range.

\section{Discussion and Conclusions}

The presented MBL approach, provides a more unified course structure, with all students progressing through topics together. Other MBL structures often feature self-paced learning modules $[6,10,11,12]$. In courses like the one here, with tiered content - each topic building directly on the previous - setting up an assessment plan separating proficiency and mastery skills sets fosters improved student mastery of core principles across the entire sequence of topics.

The increased success rate on the proficiency level work by the students is likely due to several interrelated causes, including shifted expectations and having the foundation necessary for the next topic. Students appreciate the clearly defined expectations required for the proficiency level competency (also access to a C-level grade). The instructor now also know precisely where these students have demonstrated competency at the end of a course. When competency in procedural analysis is conflated with the ability to handle more open-ended analyses and evaluate and predict behavior, students with grades of $\mathrm{C}$ often were not able to fully apply the material to solve the proficiency level problems. This, in turn, set the students up for similar struggles in the next topics.

Knowing they must demonstrate full competency on the proficiency analysis motivates preparedness in the students. The students in this course responded to the new expectation, the percentage of students demonstrating competency in the proficiency level problems on exams soared from one-third to $85 \%$. And the $15 \%$ not demonstrating competency? $95 \%$ of the time, they had achieved competency by the next exam date. As we move to the next topic in the course, all students are on track with the skills they need to tackle that next topic.

One challenge was motivating even the strongest students to prepare for the more open-ended portions of the exams. With such clear goals for the proficiency analyses, many of the best students over prepared for these problems, at the expense of the higher-order skill set. Students 
may need coaching on how to balance their preparation and how to develop the higher order skills.

\section{Works Cited}

[1] B. S. Bloom, Human Characteristics and School Learning, New York: McGraw-Hill, 1976.

[2] B. S. Bloom, "The 2 sigma problem: The search for methods of group instruction as effective as one-to-one tutoring," Educational Researcher, vol. 13, no. 6, pp. 4-16, 1984.

[3] T. R. Guskey, "Lessons of Mastery Learning," Educational Leadership, vol. 68, no. 2, pp. 52-57, October 2010.

[4] M. Henri, M. D. Johnson and B. Nepal, "A review of Competency-Based Learning: Tools, Assessments, and Recommendations," Journal of Engineering Education, vol. 106, no. 4, pp. 607-638, 2017.

[5] R. W. Tyler, Basic Principles of Curriculum and Instruction, Chicago: University of Chicago Press, 2013.

[6] K. M. DeGoede, "Competency Based Assessment in Dynamics," Salt Lake, Utah, 2018.

[7] R. M. Felder, R. Brent and M. J. Prince, "Engineering Instructional Development:

Programs, Best Practices, and Recommendations," Journal of Engineering Education, vol. 100, no. 1, p. 89-122, 2011.

[8] J. E. Froyd, P. C. Wankat and K. A. Smith, "Five Major Shifts in 100 Years of Engineering Education," Proceedings of the IEEE, vol. 100, pp. 1344-1360, 2012.

[9] L. E. Craugh, "Adapted Mastery Grading for Statics," in ASEE Annual Conference Proceedings, Columbus, Ohio, 2017.

[10] J. Mendez, "Standards-Based Specifications Grading in Thermodynamics," West Lafayette, IN, 2018.

[11] J. Mendez, "Standards-Based Specifications Grading in a Hybrid Course, Salt Lake City, Utah.," Salt Lake, Utah, 2018.

[12] S. L. Post, "Standards-Based Grading in a Fluid Mechanics Course," Ingternational Journal of Engineering Pedagogy, vol. 7, no. 1, pp. 173-181, 2017.

[13] ABET, "Criteria for Accrediting Engineering Programs, 2019 - 2020," [Online]. Available: https://www.abet.org/accreditation/accreditation-criteria/criteria-for-accreditingengineering-programs-2019-2020/\#GC3. [Accessed 16 January 2020].

[14] Mathworks, "Simscape Multibody," [Online]. Available: https://www.mathworks.com/products/simmechanics.html. [Accessed 16 January 2020].

[15] B. S. Bloom, Taxonomy of educational objectives: The classification of educational goals.Volume I, New York: David McKay Company, 1956. 